\title{
Sensitivity Analysis for Iceberg Geometry Shape in Ship-Iceberg Collision in View of Different Material Models
}

\author{
Yan Gao, ${ }^{1}$ Zhiqiang Hu, ${ }^{1}$ and Jin Wang ${ }^{2}$ \\ ${ }^{1}$ State Key Laboratory of Ocean Engineering, Shanghai Jiao Tong University, Shanghai 200240, China \\ ${ }^{2}$ COTEC Offshore Engineering Solution, Houston, TX 77079, USA
}

Correspondence should be addressed to Zhiqiang Hu; zhqhu@sjtu.edu.cn

Received 25 June 2014; Accepted 22 July 2014; Published 25 September 2014

Academic Editor: Song Cen

Copyright (C) 2014 Yan Gao et al. This is an open access article distributed under the Creative Commons Attribution License, which permits unrestricted use, distribution, and reproduction in any medium, provided the original work is properly cited.

\begin{abstract}
The increasing marine activities in Arctic area have brought growing interest in ship-iceberg collision study. The purpose of this paper is to study the iceberg geometry shape effect on the collision process. In order to estimate the sensitivity parameter, five different geometry iceberg models and two iceberg material models are adopted in the analysis. The FEM numerical simulation is used to predict the scenario and the related responses. The simulation results including energy dissipation and impact force are investigated and compared. It is shown that the collision process and energy dissipation are more sensitive to iceberg local shape than other factors when the elastic-plastic iceberg material model is applied. The blunt iceberg models act rigidly while the sharp ones crush easily during the simulation process. With respect to the crushable foam iceberg material model, the iceberg geometry has relatively small influence on the collision process. The spherical iceberg model shows the most rigidity for both iceberg material models and should be paid the most attention for ice-resist design for ships.
\end{abstract}

\section{Introduction}

Because of the promising natural resources in Arctic region and the upcoming northern sea route, marine activities in Arctic region have increased significantly in the past decade. Consequently, the possibility of ship collisions with icebergs increases with the rising number of vessels. According to a damage survey made by Finnish and Swedish maritime administration [1], around $30 \%$ of the ship structural damages during the winter of 2002-2003 are due to ship-ice interactions. Severe collision impacts may cause serious structural damage to the hull, posing a threat to the ships and local ecosystem. Against such a background, a vast amount of research has been conducted on ship-ice collision.

One approach to predict ice load during ship-iceberg interaction is carrying out the related experiments. Nevertheless, the experiment data are scarce and only limited sets of the data are available to researchers. Besides, ice rules are conventionally adopted by researchers, which are issued by the maritime authorities and classification societies. But these rules are far from enough to provide ice load assessment since they are limited to certain ship types and regions. For example, the ice load provided by the frequently employed ice class rules "Finnish and Swedish Ice class Rules" [2] is only suitable for the first-year ice condition in Baltic Sea. Therefore, a universally applicable and available prediction methodology for ship-ice collision study is required.

The numerical simulation is able to provide detailed insight of the dynamics of ice during ship-ice interaction. A valid ice material model is the premise of reliable simulation results. The discrete element method (DEM) is occasionally employed to model the iceberg, but it may lead to a lack of generally accepted mathematical foundation and therefore often results in purposely built algorithms for a certain application [3]. The finite element method (FEM) is generally utilized on the other hand. Taking these facts into consideration, the FEM is adopted in this paper.

A good understanding of the iceberg mechanics properties is of crucial importance to model a valid ice material model. Due to the fact that the high homologous temperature of ice occurs in nature, $T_{h}>0.8$, the ice mechanics behavior strongly depends on strain rate. At a low strain rate, the ice mechanics behavior is dominated by creep and 
microcracking. Thus, the ice can be treated as an elasticviscous-plastic material with a ductile failure mode [4]. On the other hand, the ice behaves as a linear elastic material with brittle failure when the ice crystals are at a high strain rate. According to Schulson's research [5], the critical transition strain rate between the ductile and brittle response is about $10^{-3} \mathrm{~s}^{-1}$. For the simulation cases in this paper, the icebergs collide with ships at a relatively high speed, and then the corresponding strain rate is higher than the critical value. Taking this fact into consideration, the iceberg is treated as a material with elastic properties.

Spalling, extruding, and cracking accompanied by recrystallization all occur when ice fails, so modeling a material which can completely capture the ice behavior during the ship-iceberg collision is a challenging task. For engineering purposes, a representative load model is applied rather than a physical correct material model [6]. Thus, if the ice load provided by an ice material model is consistent with the experiment data or ice rules, the material model is assumed to be valid [7]. The ice load during the ship-ice interaction is conventionally indicated by a pressure-area curve. Sanderson [8] presented a pressure-area relationship by combining a large number of data sources and ice interactions. Materson et al. [9] proposed a revised pressure-area equation $P=$ $7.4 A^{-0.7}$ which was also adopted by ISO $\backslash$ CD (19906) [10]. The aforementioned pressure-area relationship shows a definite decrease in pressure with increasing area. But there is a substantial divergence of opinions on the ice pressure-area relationship. The ice impact pressure on structure becomes a function of contact area if linear fracture mechanics is applied to simulate the ice [11]. Timco and Sudom argued that there were other factors such as loading rates and ice failure modes which were more important than the contact area in predicting ice pressure in many cases [12]. An increase in pressure with increasing area is observed in Gagnon's experiments [13]. Therefore, further study in the ice impact load is required to gain a generally accepted result.

Since ice is a very complicated material, a generally accepted ice material model for ship-iceberg collision has not been well established. Jebaraj et al. [14] considered that the ice has elastic properties and tensile fracture mode. But the failure reference number used for failure initiation does not have a strong theoretical basis. Von Bock et al. [15] used a Lemaitre damage model to simulate the model-scale ice and obtained good results. Nonetheless, considering the distinction between the model-scale ice and the natural ice, this material model may not be suitable to predict ice load in reality. Gagnon [16] presented a crushable foam material in FEM simulation. Nevertheless, this foam material does not contain many physical parameters of the ice behavior and it must be used with extreme care on other scenarios compared with the specific one it is calibrated towards. In conclusion, a material model closer to ice natural mechanics is necessary in the FEM simulation and hence further study is needed.

Different iceberg geometry shapes contribute to quite different ship-iceberg interaction processes. Some icebergs penetrate the hull structure, leaving ships at risk. While some icebergs crush easily in the collision. One primary purpose of the present analysis is to estimate the iceberg geometry effect on the collision scenario. Another purpose is to define the most dangerous iceberg shape to design against, giving support for ice-resist design for ships. Five different geometry icebergs are modeled in the present collision simulation. Two iceberg material models are utilized for comparing the geometry effects. The impact force and energy dissipation are analyzed and compared to illustrate the different collision processes.

\section{Numerical Modeling and Simulation Implementation}

In this section, comprehensive ship-iceberg collision analyses are carried out using five different shape iceberg models. An elastic-plastic material model and a crushable foam model proposed by Gagnon [13] are utilized for comparing the different iceberg geometry effects on the collision process.

2.1. Ice Material Modeling. The main stages that the ice undergoes during ship-iceberg interaction are illustrated in Figure 1 when the ice is simulated by the elastic-plastic material model. At the beginning, the ice is elastic and the stress-strain relationship is governed by Hook's law. The ice compressive strength increases with rising hydrostatic pressure; thus, a multisurface yield criterion "Tsai-Wu" yield function [17], which includes hydrostatic pressure, is adopted to determine the critical state between elastic and plastic responses, see (1). When the plastic deformation starts, the flow theory is adopted to deal with the stress-strain relationship. Considering the stress computation in the plastic state, semi-implicit return mapping algorithm [18] is employed to map the stress back to the yield surface. The stress will flow on the yield surface until the failure criterion is satisfied. The empirical failure criterion proposed by Liu et al. [19] is adopted in this paper. This failure criterion is based on the effective plastic strain and hydrostatic pressure, see (2). If the effective plastic strain is larger than the failure strain or the pressure is no larger than the cut-off pressure, the ice element will fail and be eroded in the simulation. The element eroding may be a violation of the principle of mass conservation. Nevertheless, in reality, the failed ice grains might turn to fluid as observed in the experiment [13]. Finally, this material model is incorporated into the LS-DYNA software by user defined subroutine:

$$
f\left(p, J_{2}\right)=J_{2}-\left(a_{0}+a_{1} p+a_{2} p^{2}\right)=0,
$$

where $a_{0}=22.93 \mathrm{MPa}^{2}, a_{1}=2.06 \mathrm{MPa}, a_{2}=-0.023$ in the present analysis:

$$
\begin{aligned}
\varepsilon_{\mathrm{eq}}^{p} & =\sqrt{\frac{2}{3} \varepsilon_{i j}^{p}: \varepsilon_{i j}^{p}}, \\
\varepsilon_{f} & =\varepsilon_{0}+\left(\frac{p}{p_{2}}-0.5\right)^{2}, \\
P & <P_{\text {cut-off }},
\end{aligned}
$$

where $P_{\text {cut-off }}$ is set to be $-2 \mathrm{MPa}$ and $\varepsilon_{0}$ equals 0.1 in the present analysis. 


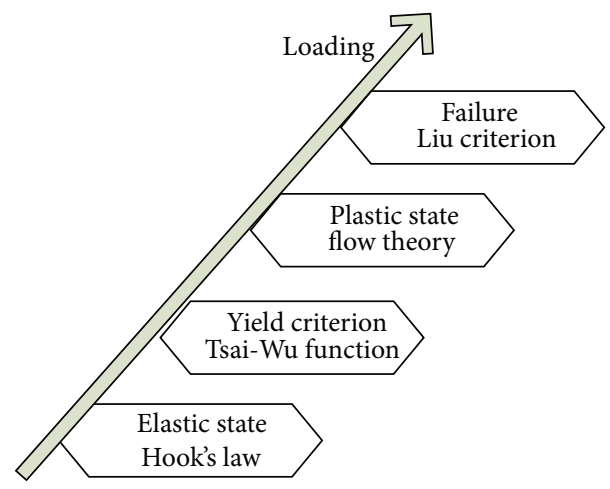

FIGURE 1: Ice development process of the elastic-plastic material.

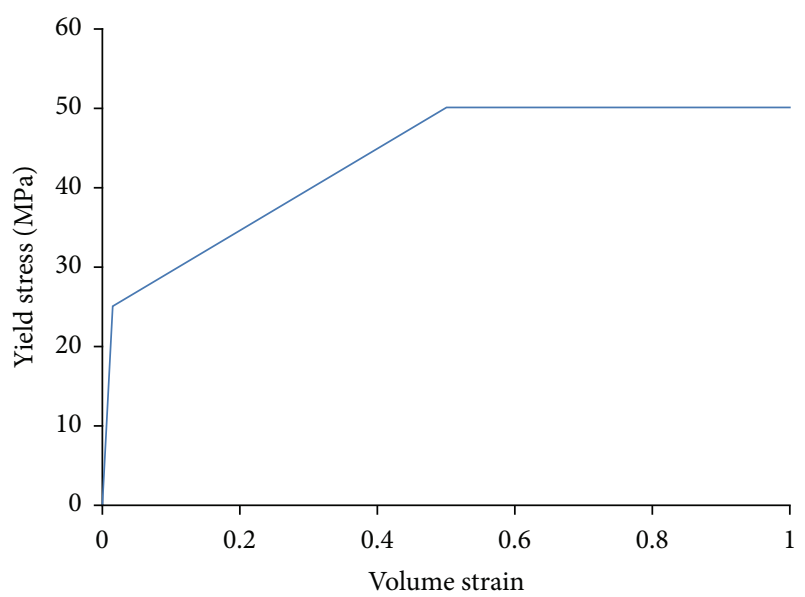

FIGURE 2: Volume strain-yield stress relationship of the crushable foam material.

The crushable foam material is also utilized to estimate the geometry sensitivity, compared with the aforementioned elastic-plastic material model. The stress-strain relationship of the crushable foam model shown in Figure 2 is based on Gagnon's experiment data [20]. The yield stress is $25 \mathrm{MPa}$ when the volume strain is 0.015 . And when the volume strain is beyond 0.5 , the yield stress will remain $50 \mathrm{MPa}$. Hourglass control is important for this foam material because the hourglass energy would easily go beyond the allowable range. The rigid hourglass control method provided by LSDYNA software [21] is adopted in the principle of the lowest ratio of hourglass energy to total energy. The fundamental ice mechanics parameters for both materials are listed in Table 1.

2.2. Collision Scenario Parameters. The collision scenario is defined as follows: the iceberg model strikes the FPSO side structure with a constant speed of $2 \mathrm{~m} / \mathrm{s}$. The computation time is 1 second due to the balancing of the computation time and accuracy. A rigid surface is attached aft to each iceberg to supply an even force distribution into the local part of the iceberg. In addition, the constant velocity is given to one node in the rigid surface to push the iceberg model forward. Since the iceberg model and the rigid surface share nodes, no contact area is defined between them. The boundary of the FPSO side structure is fixed in all freedom degrees to compensate for the none-modeled structure. The different geometry iceberg models and FPSO side structure model are illustrated in Figure 3. The collision front view and side view (locally zoomed) are shown in Figure 4 . The details about the models are summarized in Tables 2 and 3. The choice of "contact_automatic_surface_to_surface" with soft option 2 in code LS-DYNA can generate more accurate simulation results than the generally used ones when the properties of the two contact materials vary greatly. The choice of "contact_eroded_single_surface" is utilized to simulate ice internal contact. The friction coefficient is set to 0.3 for both contact algorithms. The size of the ice elements is set to be $50 \mathrm{~mm} * 50 \mathrm{~mm} * 50 \mathrm{~mm}$, which is accurate enough to obtain a convergent simulation result.

\section{Results and Discussion}

3.1. Simulation Results. The results of numerical simulations are obtained, including the data of contact force, energy dissipation, and structural deformation. The contact pressure in the spherical iceberg model collision case using the elasticplastic material is displayed in Figure 5 as an example. Both high pressure zones (HPZs) and low pressure zones (LPZs) which are generally considered as the characteristics of ice mechanics are observed in the contact area. The highest pressure in HPZs is about $80 \mathrm{MPa}$, and the value agrees well with Liu et al. simulation result [22]. The average pressure in the surrounding LPZs is about $2 \mathrm{Mpa}$. The fact that locations of the HPZs and LPZs change with time is another obvious feature of ship-iceberg interaction, which has also been observed in the simulation.

The pressure-area relationship is commonly employed to denote the ice mechanics during ship-iceberg interaction. The pressure is defined as the collision force divided by the nominal contact area. Taking the ship-spherical iceberg collision scenario as an example, the pressure-area curves obtained by the elastic-plastic material model and the crushable foam material model are compared in Figure 6. The two curves are similar, indicating similar ice mechanics in the presented cases. When the contact area is larger than $1.5 \mathrm{~m}^{2}$, the average pressure stays at about $5.5 \mathrm{MPa}$, which is consistent with ISO (19906) standard [10].

As mentioned above, ice mechanics properties of both the material models are similar in the spherical iceberg model case. Thus, the outer shell deformation and the largest stress place do not differ obviously in both material models. The outer shell deformation with elastic-plastic material at the moment of $t=1 \mathrm{~s}$ is shown in Figure 7. And the picture indicates that the outer shell remains intact, which means that there is no oil or gas leakage in this simulation case. The largest stress with the value of $469.36 \mathrm{MPa}$ takes place on the longitudinal web just behind the contact region of the outer shell, as Figure 8 displays. The stiffeners fracture before the iceberg penetrates the outer shell in the simulation. Thus, the FPSO side structure should be strengthened if it is designed for sailing in the ice-covered regions. 
TABLE 1: Ice mechanics parameters.

\begin{tabular}{lcc}
\hline Iceberg details & Elastic-plastic material & Crushable foam material \\
\hline Density kg/m ${ }^{3}$ & 900 & 900 \\
Young's modulus $\mathrm{MPa}$ & 9500 & 9500 \\
Poisson's ratio & 0.3 & 0 \\
Material & ${ }^{*}$ MAT_USER_DEFINED & ${ }^{*}$ MAT_CRUSHABLE FOAM \\
\hline
\end{tabular}

TABLE 2: FPSO segment geometry details.

\begin{tabular}{lccc}
\hline & \multicolumn{3}{c}{ FPSO segment details } \\
\hline Length overall $\mathrm{m}$ & 288 & Density kg/m ${ }^{3}$ & 7890 \\
Moulded breadth m & 65 & Young's modulus GPa & 2.1 \\
Moulded depth m & 29.4 & Poisson's ratio & 0.3 \\
Draft m & 22 & Yield stress MPa & 289 \\
Side shell spacing m & 3.4 & Failure strain & 0.35 \\
Outer shell thickness mm & 20 & Typical element dimension mm & 225 \\
Side stringer thickness mm & 14 & Element type & *SECTION_SHELL \\
Inner shell thickness mm & 15 & Segment length m & 35 \\
Segment height m & 26 & Element number & 105664 \\
Length between perpendiculars m & 281 & Material type & * MAT_PIECEWISE_LINEAR_PLASTICITY \\
\hline
\end{tabular}

TABLE 3: Iceberg models geometry details.

\begin{tabular}{lccccc}
\hline Geometry & Sphere & Cube & Prism & Cone & Ellipsoid \\
\hline Size $\mathrm{m}$ & $R=2$ & $L=3$ & $L=3$ & $R 1=2.5 R 2=1.5 H=3.5$ & $R 1=2 R 2=3$ \\
\hline
\end{tabular}

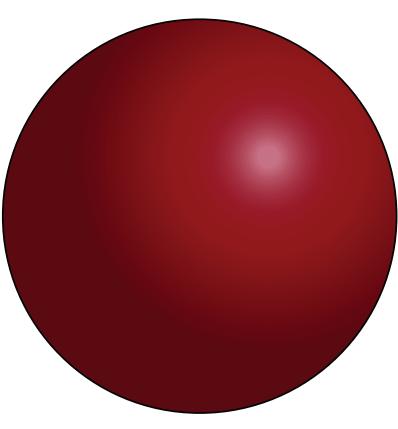

Sphere

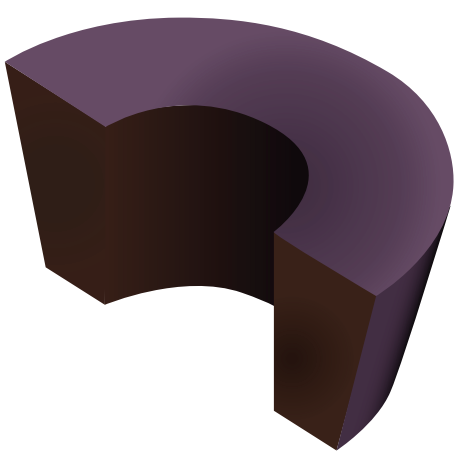

Cone

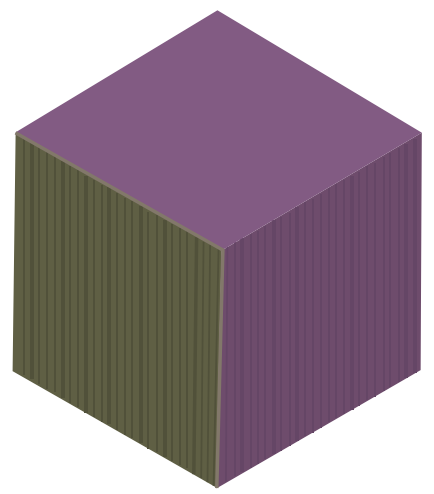

Cube

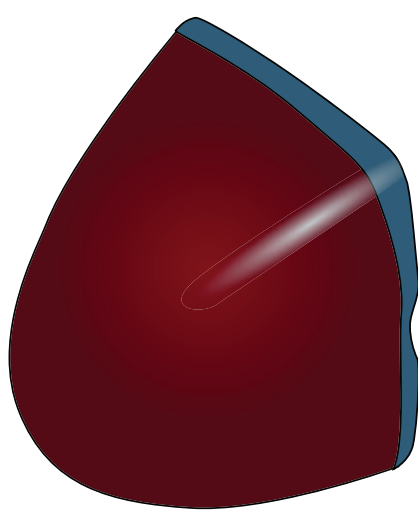

Ellipsoid

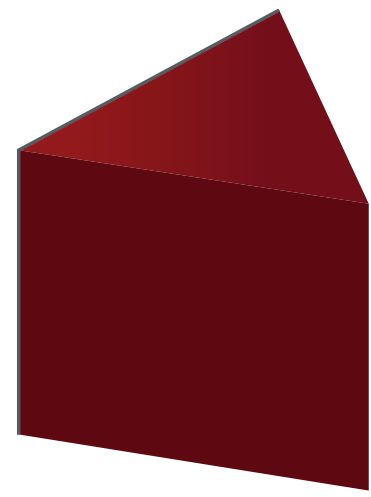

Prism

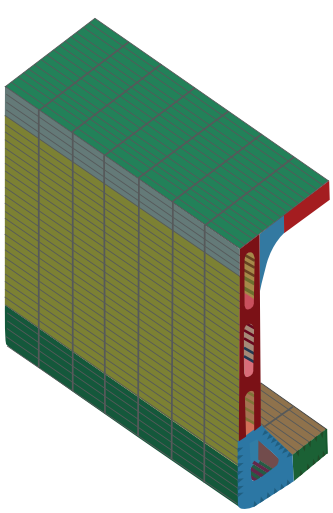

FPSO side structure

FIGURE 3: Ship-iceberg collision models. 


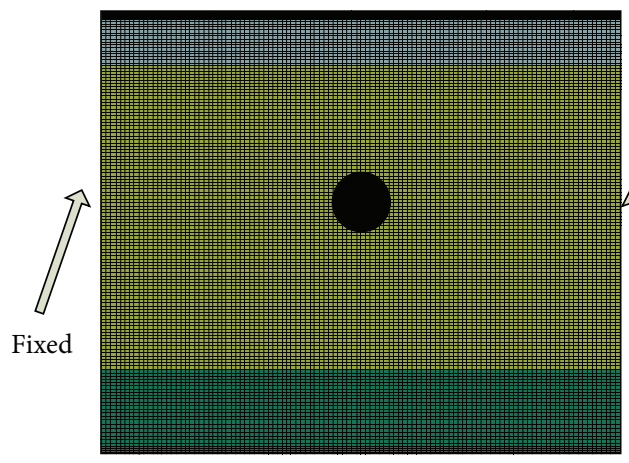

Collision scenario in front view

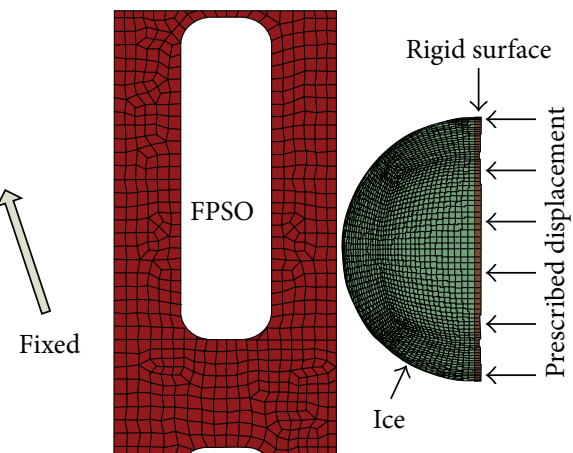

Collision scenario in side view (locally zoomed)

FIGURE 4: Ship-iceberg collision scenario schematic.

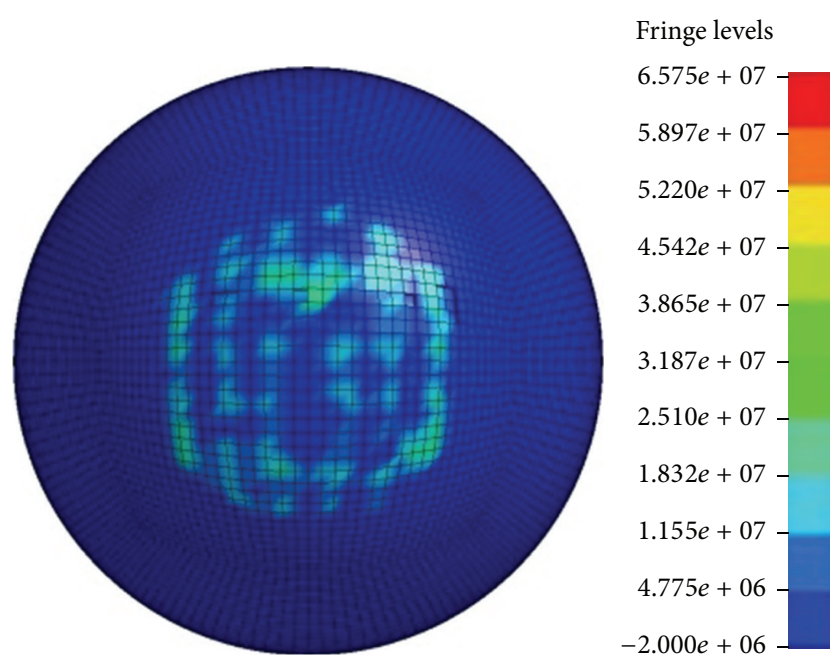

FIGURE 5: Contact pressure at $t=0.8 \mathrm{~s}$.

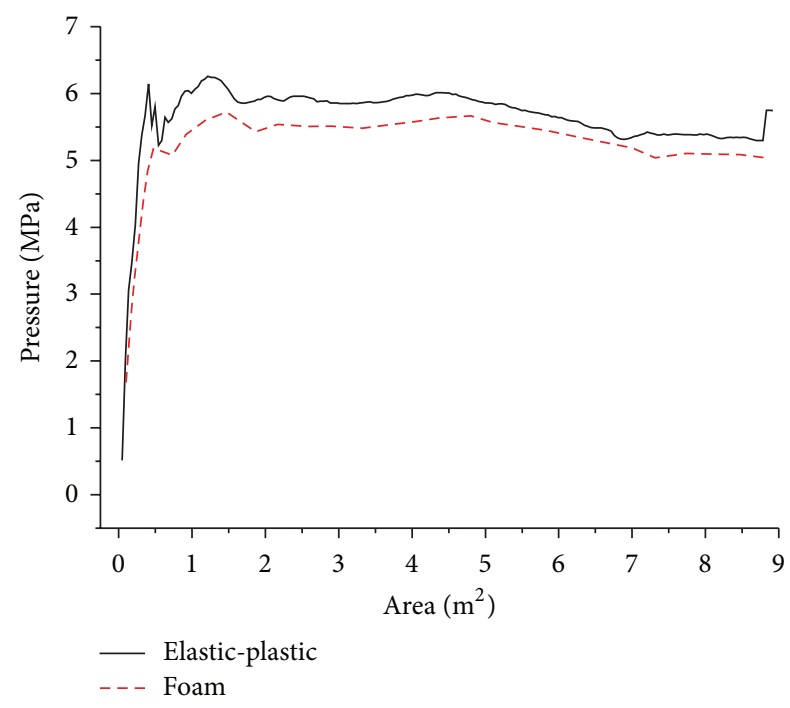

FIgURE 6: Pressure-area relationships.

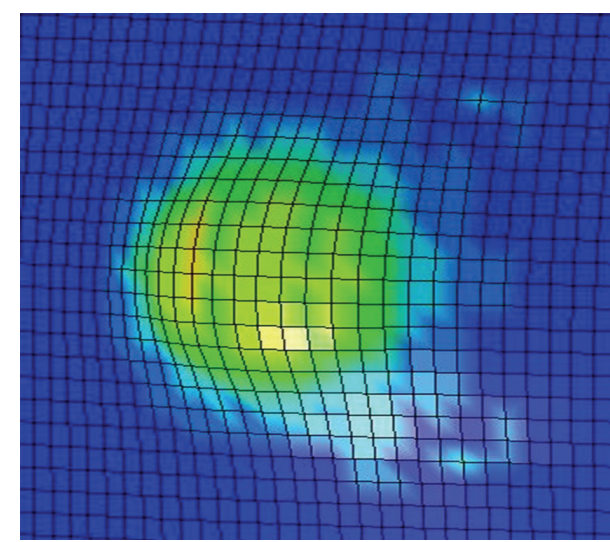

Figure 7: Outer-shell deformation.

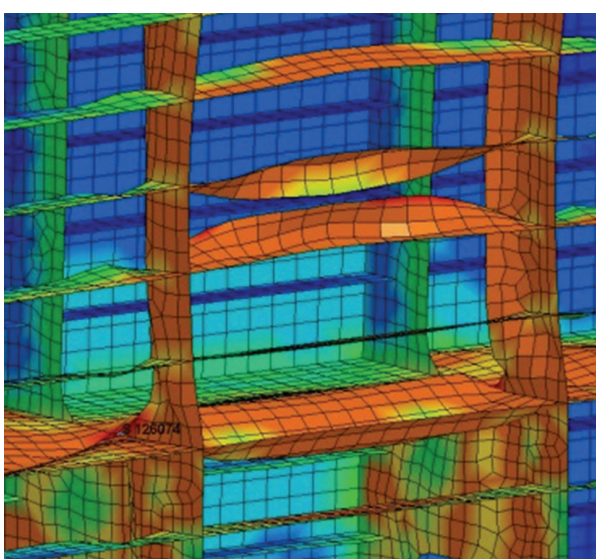

FIGURE 8: The largest stress place.

3.2. Iceberg Geometry Shape Sensitivity Analysis. As mentioned before, five different iceberg models are utilized to investigate the geometry shape sensitivity in view of the two comparative material models. The deformation situations of the spherical and conic iceberg cases for the foam material model are demonstrated in Figure 9. Both icebergs can indent the hull structure without large deformation. Therefore, it can be concluded from the figure that the iceberg geometry 


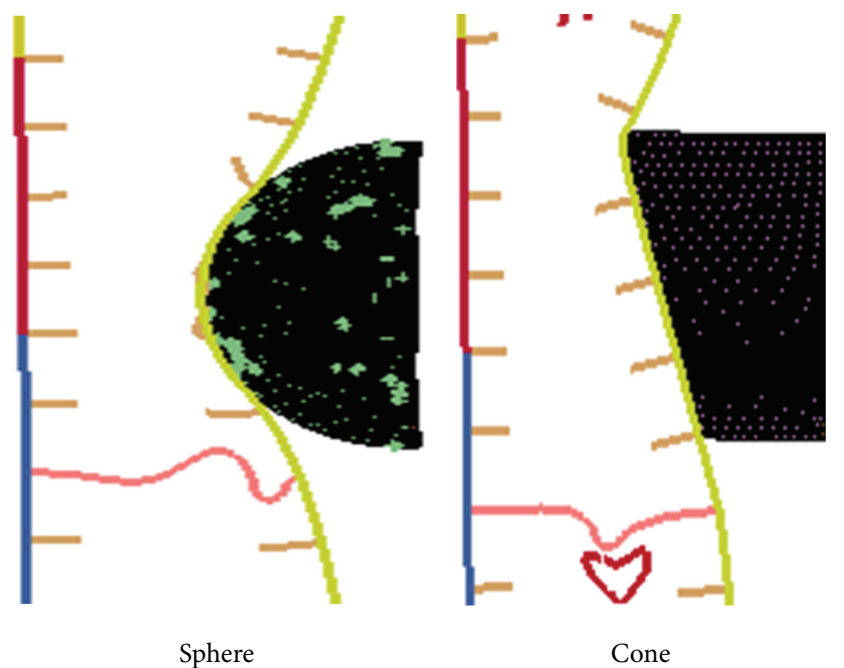

FIgURE 9: Deformation plot of the crushable foam material.

shape does not have a significant effect on collision process. Giving a deeper insight into the collision process, the ice quickly reaches its limit volume strain and then behaves nearly rigidly.

On the contrary, the collision processes vary considerably between different iceberg geometry models when the elasticplastic material is employed. The blunt iceberg model acts nearly rigidly and shows similar property as one of the crushable foam material models. Compared with the blunt iceberg model, the sharp model crushes easily. The deformation situations for the spherical and conic iceberg model cases are shown in Figure 10, respectively. Only a few elements of the spherical iceberg model are observed to fail in the simulation, as the first picture of Figure 10 shows. In addition, the outer shell undergoes large deformation and the side stringers bend severely in that case. On the contrary, a great number of ice elements of the conic iceberg model fail. And the conic iceberg model is almost totally eroded in the end. Therefore, due to the crushing of the conic iceberg model, the hull deformation is less than that of the spherical case. On this qualitative observation of the ship-iceberg collision simulation, it indicates that the iceberg shape does have an effect on the collision response for the elastic-plastic material model.

In order to conduct a more quantitative geometry sensitivity study, the ice dissipated energy in these four cases is compared and illustrated in Figure 11(a). The energy dissipated by spherical iceberg is below $1 \mathrm{MJ}$ for both material models, proving the rigid property assumption of spherical iceberg as discussed in the above. The energy dissipated by conic iceberg model still remains at a low level for the crushable foam material. Nevertheless, the energy dissipated by conic iceberg model increases rapidly with the hull deformation for the elastic-plastic material. More specifically, the energy dissipated by conic iceberg model reaches as high as $11 \mathrm{MJ}$ at the end of the simulation. Through the estimation of eroded energy in the simulation, the eroded internal energy accounts for the main part of the energy dissipated

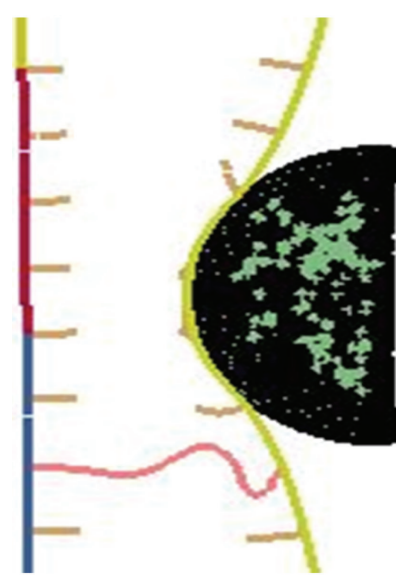

Sphere

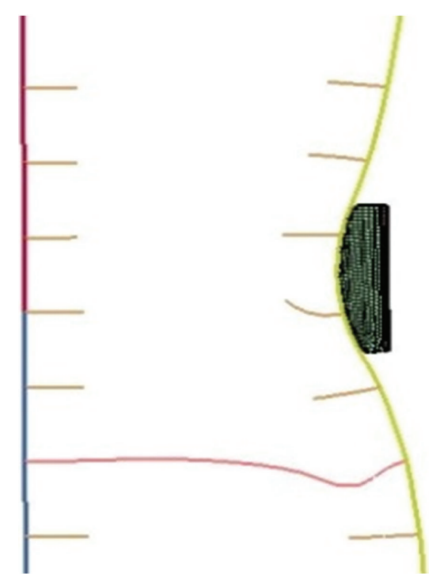

Cone
FIGURE 10: Deformation plot of the elastic-plastic material.

by conic iceberg model. Thus, this result is consistent with the aforementioned observation of the conic iceberg severe crushing. To gain a more directly perceived view, the crushing processes of prism model and spherical model are shown in Figure 11(b).

On the purpose of analyzing the iceberg shape sensitivity more detailedly, the results of resistance force, total energy dissipation, and the ratio of dissipated energy by iceberg to total dissipated energy are investigated from the numerical simulation results, as is shown in Figures 12, 13, and 14. The hull deformation is defined as the largest displacement of the nodes on the hull contact surface. The ratio of energy dissipated by iceberg to total energy dissipation reflects the relative strength relationship between the ship and the icebergs. For the sake of defining the most dangerous iceberg shape, the energy ratio is fully discussed in the following. The energy ratio of the spherical iceberg model is the lowest among all the ratios at a certain time, indicating the hardest iceberg property of the spherical iceberg during ship-iceberg collision. The corresponding hull deformation of spherical iceberg model is hence the largest of all iceberg models, indicating the highest risk level of hull damage in all simulation cases. In conclusion, the spherical shape is the most dangerous to design against.

Considering the crushable foam material models, the resistance force and energy dissipation do not vary obviously for different iceberg geometry shapes. All of the energy ratios are nearly zero in the later collision stage. Considering the collision process, the iceberg models undergo initial deformation and then quickly harden and indent the hull. On the contrary, the collision process is different for different iceberg shapes when the elastic-plastic material model is employed. The energy ratios are about 0.4 when the icebergs are in sharp shapes, indicating a "softer" contact in these situations. And due to the crushing of the iceberg, the hull deformations are less than $1 \mathrm{~m}$, which are far smaller than the iceberg geometry sizes. As to the blunt iceberg model, the energy ratios are in the same range of the ones of the foam model. In summary, the iceberg geometry shapes do 


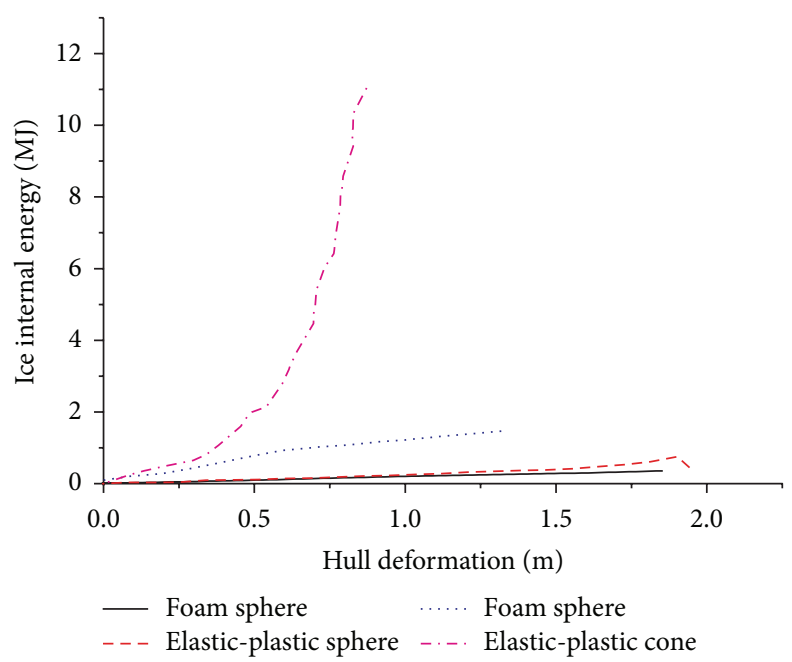

(a)

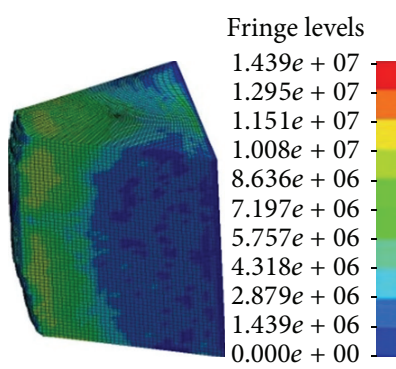

$t=0.5 \mathrm{~s}$

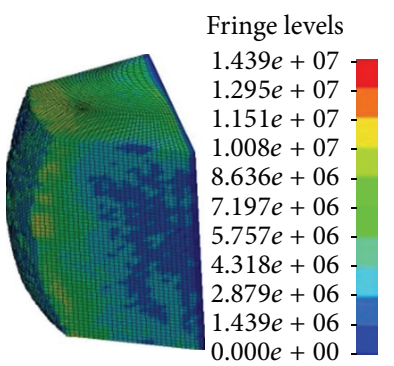

$t=1 \mathrm{~s}$

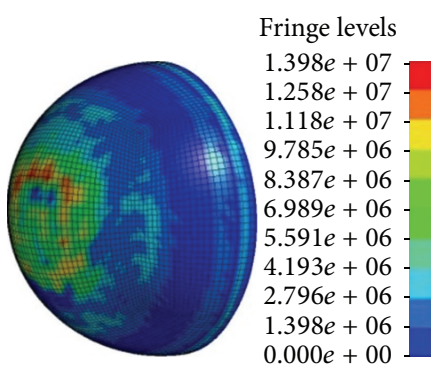

$t=0.5 \mathrm{~s}$

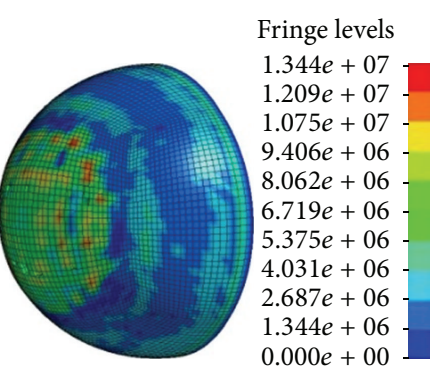

$t=1 \mathrm{~s}$

(b)

FIGURE 11: (a) Energy dissipated by ice with the material models. (b) Prism and spherical iceberg model crushing processes.

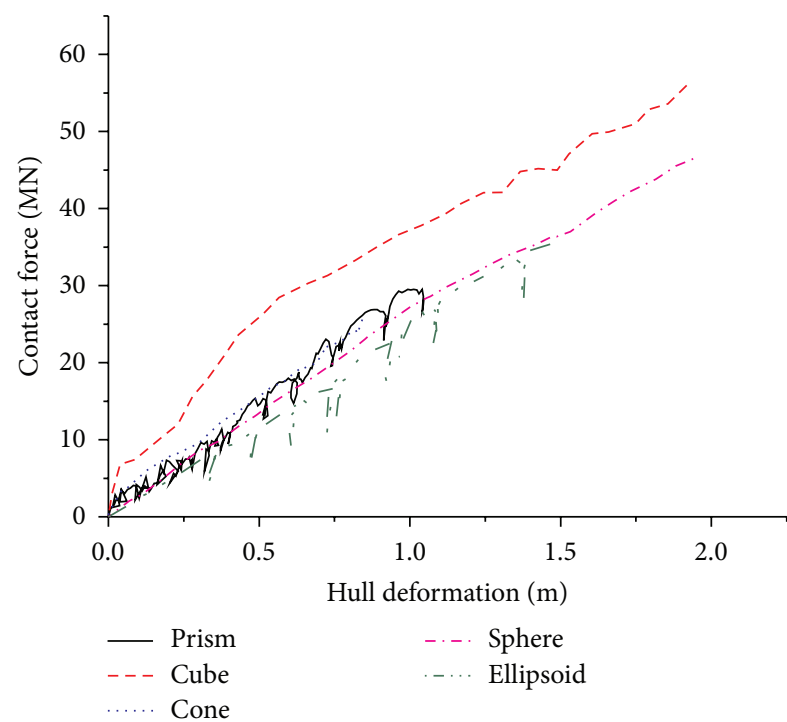

(a) Elastic-plastic material

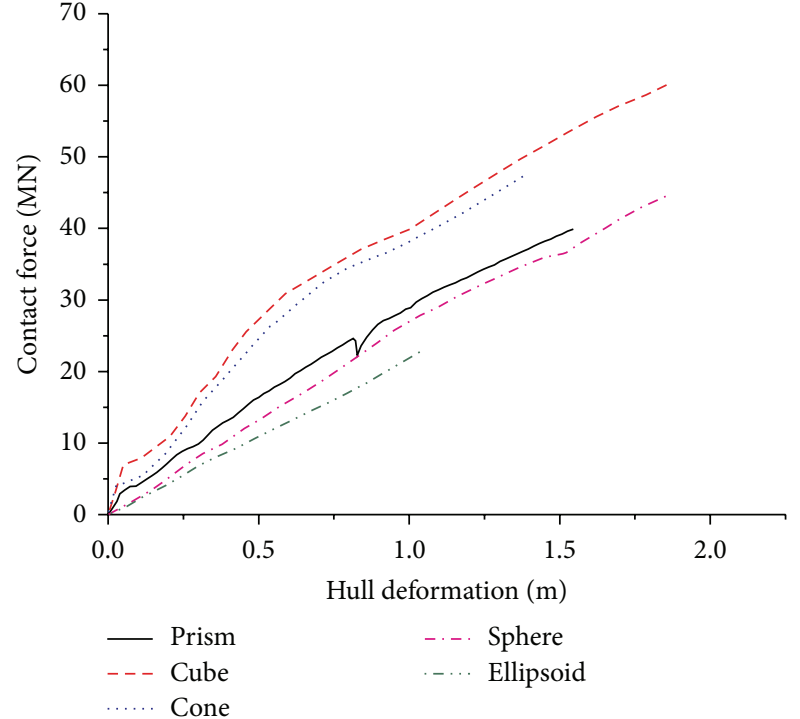

(b) Crushable foam material

FIGURE 12: Total resistance forces for both material models. 


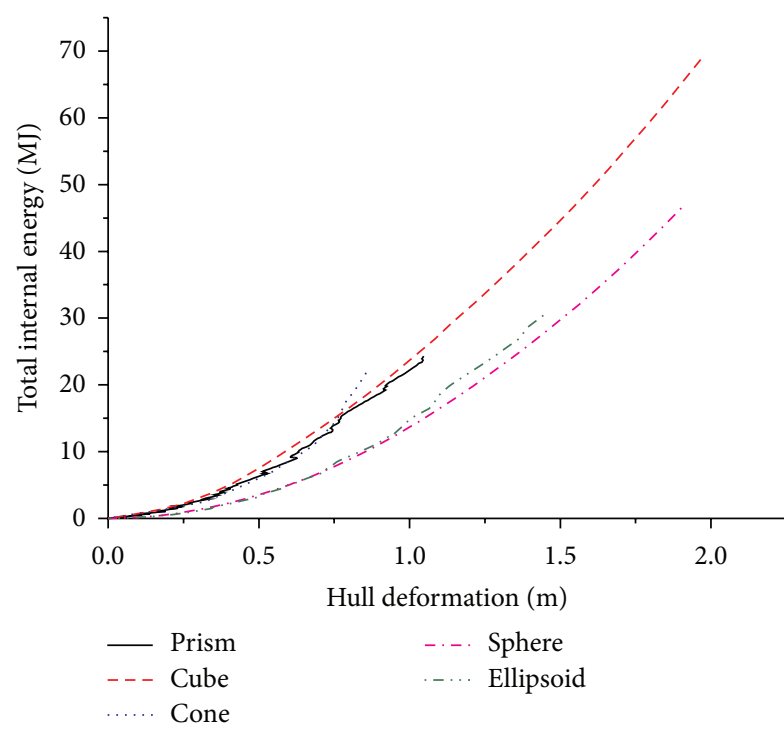

(a) Elastic-plastic material

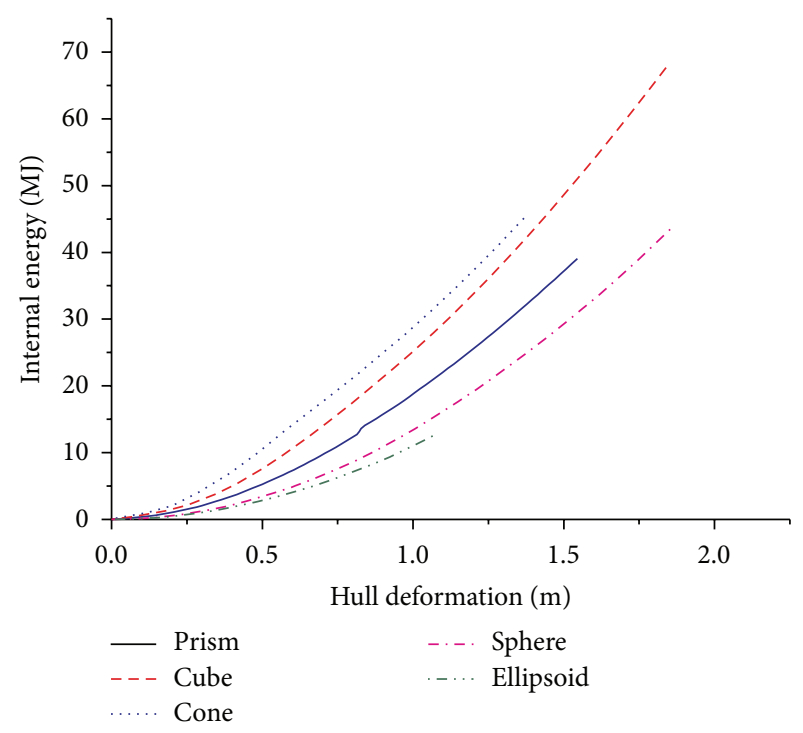

(b) Crushable foam material

FIGURE 13: Total energy dissipation for both material models.

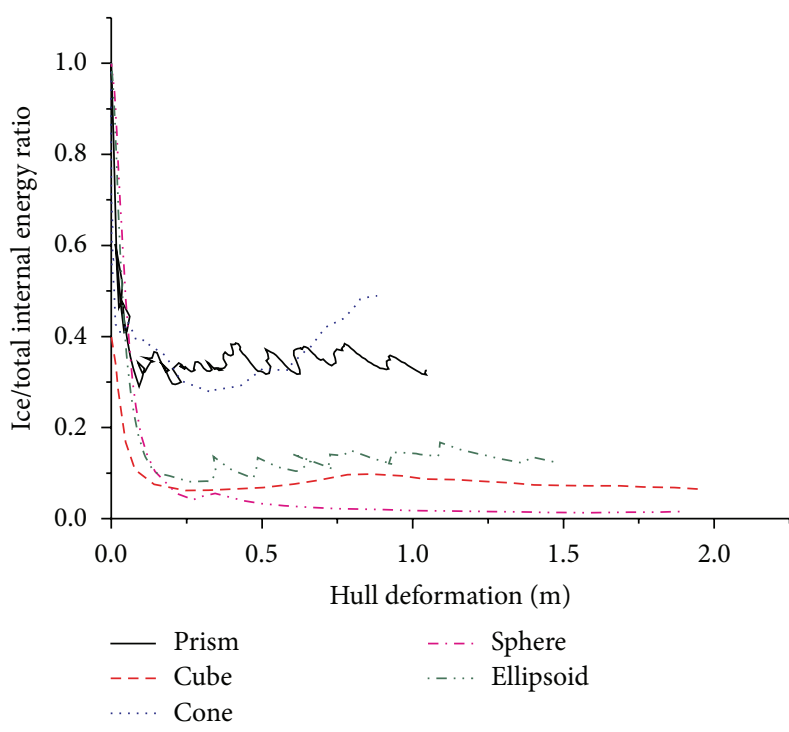

(a) Elastic-Plastic material

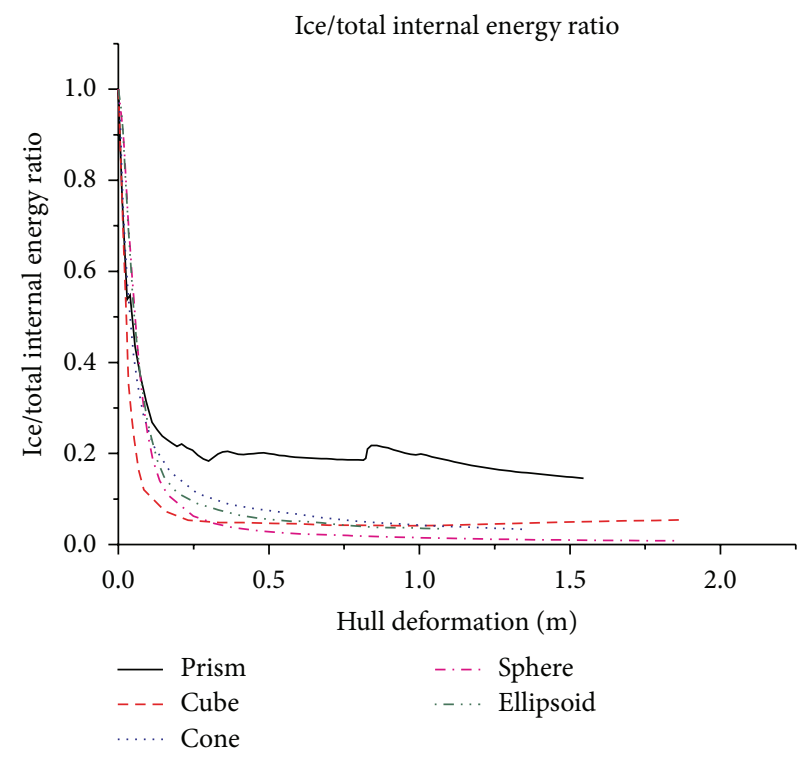

(b) Crushable foam material

FIGURE 14: Ratios of ice energy dissipation to total energy dissipation for both material models.

have a significant effect on collision results when the elasticplastic material is used. Although the iceberg shape effect has been studied by some researchers, the mechanics explanation has not been fully developed. The possible explanation is elaborated as follows. Compared with the ice elements of the sharp iceberg models, the ice elements of the blunt iceberg models in the contact area are highly confined by the surrounding elements; thus, the hydrostatic pressure is at a relatively high level; hence, the deviator stress is lower and then the effective strain is lower. Therefore, the ice elements of the blunt iceberg models are less likely to fail, leading to the rigid properties of the blunt iceberg models. On the contrary, the sharp iceberg models crush easily during the ship-ice interaction.

3.3. Other Collision Parameters Sensitivity Analyses. Besides the geometry sensitivity analysis, other collision parameters' effects on the simulation results are also investigated for comparison. The sensitivity analyses of ship-iceberg collision with respect to impact velocity and water effect are conducted in this section and the velocity sensitivity analysis is introduced firstly. The field measurement data of Orden experiment [23] shown in Figure 15(a) indicates that the 


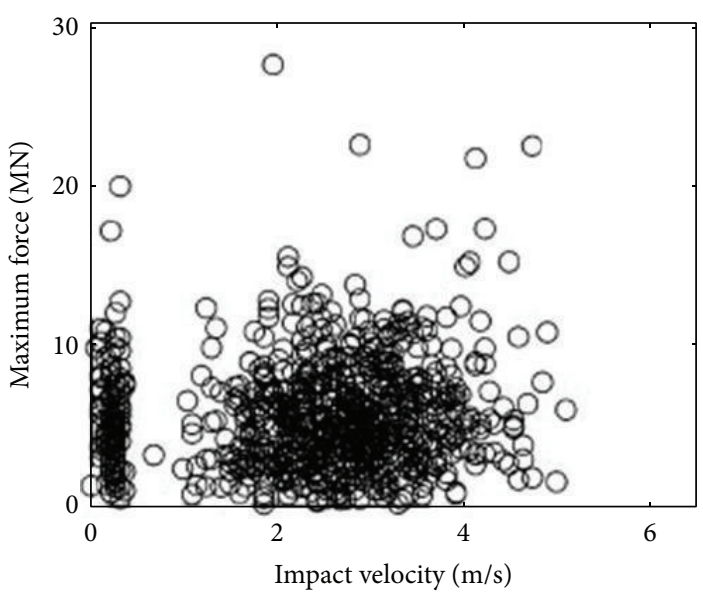

(a) Field measurement data of Orden experiment

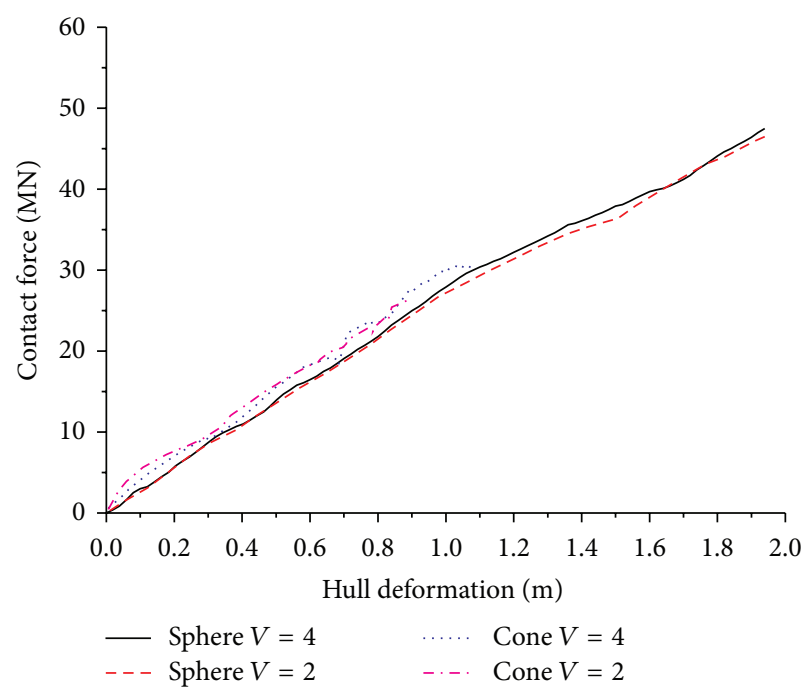

(b) Contact force

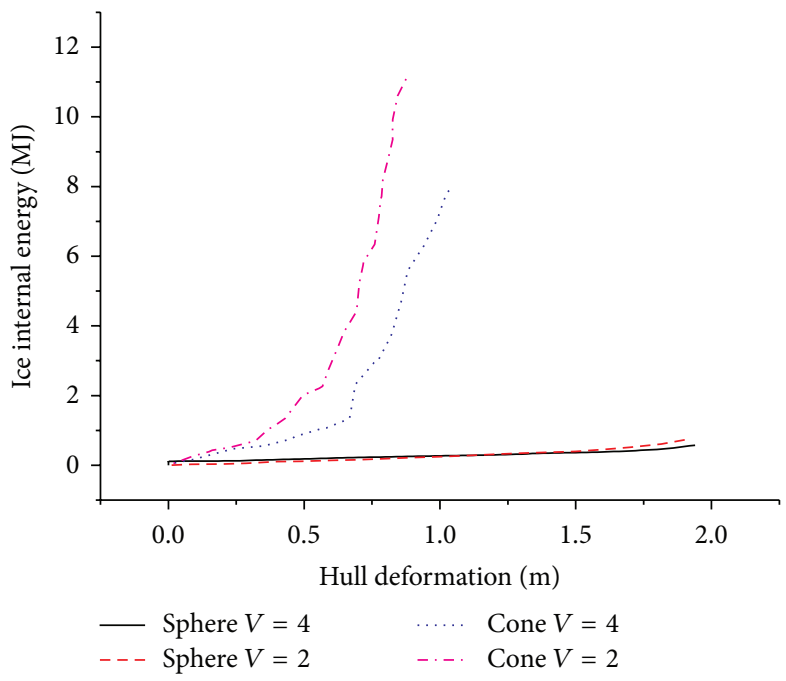

(c) Energy dissipated by ice

FIGURE 15: Velocity sensitivity analyses.

majority of ramming velocities fall into the range of $2 \mathrm{~m} / \mathrm{s} \sim$ $4 \mathrm{~m} / \mathrm{s}$. Therefore, the collision situations with $V=2 \mathrm{~m} / \mathrm{s}$ and $V=4 \mathrm{~m} / \mathrm{s}$ are investigated, respectively. Taking the elasticplastic material model cases for example, the contact force and energy dissipated by ice of spherical and conic iceberg models are shown in Figures 15(b) and 15(c), respectively. It is manifested that the impact velocity does not have significant effects on contact force, as is shown in Figure 15(b). The independence of velocity is probably due to the fact that, in the ice material models, the influence of strain rate effect is not taken into consideration. As is shown in Figure 15(c) with respect to the spherical iceberg model, the iceberg energy dissipation is approximately the same as the two impact velocities. Thus, it can be concluded that, when the iceberg geometry is blunt, energy dissipated by ice is not sensitive to impact velocity. On the other hand, the impact velocity does make some difference on iceberg energy dissipation in the case of the sharp iceberg models. The energy dissipated by ice with respect to the conic iceberg model changes to a certain extent for different velocities. The possible reason is that the ice element strain gradient increases in one load step with the increasing velocity. Thus, the energy dissipated by ice may be larger with a higher velocity at the same hull deformation. Consequently, if energy dissipated by ice with sharp local shape is investigated with the elastic-plastic material model, the influence of the ramming velocity should be taken into consideration. As to the crushable foam material, the changes of the simulation results because of the impact velocity can be ignored.

The effect of water is not considered in the above comprehensive simulations; thus, a sensitivity analysis of water effect is carried out by simply using added mass method. The added mass coefficient is assumed to be constant and equal to 0.5 for the ice mass [24]. The water effect is estimated in view of the total dissipated energy and the energy dissipated by ice, which are estimated in the ship-spherical iceberg collision 


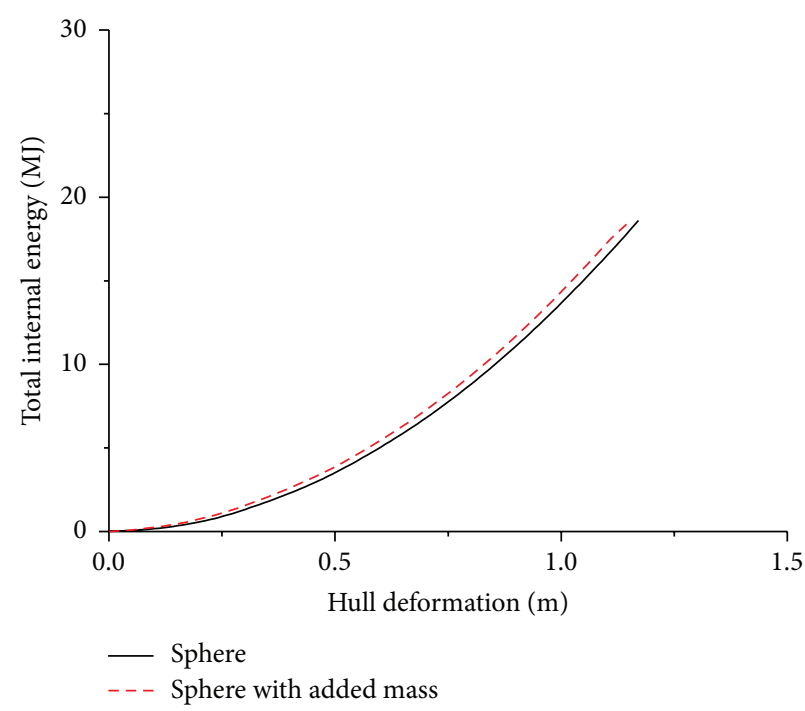

(a) Total dissipated energy

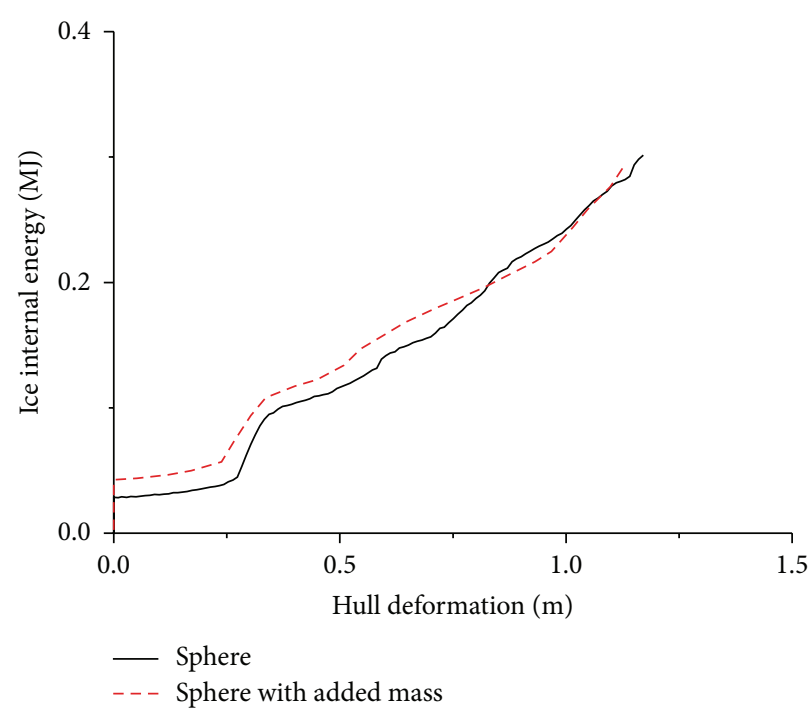

(b) Energy dissipated by ice

FIGURE 16: Water effect on ship-spherical iceberg collision.

cases, as is shown in Figure 16. The total energy dissipation of the added mass case is almost the same as the original one and the discrepancy between the energy dissipated by ice can be ignored. Therefore, when the water effect is simulated only by added mass, the effect on the energy dissipation is not significant. Nevertheless, if the damping and hydrodynamic effect are considered, there may be some different results. The focus of the simulation is to estimate the internal mechanics; thus, the water effect is simplified by added mass.

The numerical simulation problems, such as the negative volume and the hourglass control, are paid a lot of attention in the simulation. The control of negative volume is important because of the explicit finite difference method in LS-DYNA. When the crushable foam material model is applied, this problem is especially crucial. A convergent study is conducted by utilizing different ice element sizes. Then, the element length is decided to be $50 \mathrm{~mm}$ to gain the most convergent simulation results. In addition, in the case of the prism iceberg model of the crushable foam material model, element distortion occurs at the later stage of simulation. A few ice elements on the contact sharp edge fail due to the negative volume. So, the ratio of the dissipated energy by iceberg to the total dissipated energy is a little higher than the ratios of other geometry models. In order to define the most suitable hourglass control method for the crushable foam material, a sensitivity analysis is also carried out by adopting different hourglass control methods. Finally, the rigid hourglass control method is selected in the simulation, as is mentioned before.

\section{Conclusion}

The ship-iceberg collision scenario is simulated with finite element method in this paper. The focus of the simulation is the iceberg geometry shape effect on collision process. The elastic-plastic material is applied to simulate the ice material model, and the crushable foam material is also used for comparison. In summary, the local shape of the iceberg does affect the responses of ship-iceberg collision for some cases. The most important results are shown as follows.

(1) The iceberg local shape does have a significant effect on ship-iceberg interaction process when the ice is simulated by the elastic-plastic material model.

(2) The blunt iceberg model can penetrate the hull while the sharp iceberg model tends to be crushed easily for the elastic-plastic model.

(3) If the iceberg is simulated by the crushable foam material, the simulation results are not sensitive to the iceberg local shape.

(4) The spherical shape is the most dangerous shape to design against in terms of the hardest ice strength. The hull structure undergoes large deformation in the contact area, and it should be ice-strengthened when shipping in Arctic region.

\section{Nomenclature}

$T_{h}: \quad$ Homologous temperature

$P: \quad$ Ship-iceberg interface pressure

A: $\quad$ Nominal contact area

$J_{2}$ : Second invariant of deviatoric stress tensor

$p: \quad$ Hydrostatic pressure

$a_{0}, a_{1}, a_{2}$ : Elastic-plastic material constants

$\varepsilon_{\text {eq }}^{p}: \quad$ Effective plastic strain

$\varepsilon_{f}: \quad$ Failure strain

$\varepsilon_{0}: \quad$ Initial failure strain

$P_{2}$ : $\quad$ Larger root of the yield function

$P_{\text {cut-off: }} \quad$ Cut-off pressure. 


\section{Conflict of Interests}

The authors declare that there is no conflict of interests regarding the publication of this paper.

\section{References}

[1] S. Hänninen, Incidents and Accidents in Winter Navigation in the Baltic Sea, Winter 2002-2003, Finnish Maritime Administration, 2005.

[2] F. M. Administrations, Finnish-Swedish Ice Class Rules, 2008.

[3] A. Gürtner, Experimental and numerical investigations of icestructure interaction [Ph.D. thesis], Norwegian University of Science and Technology, 2009.

[4] G. W. Timco and W. F. Weeks, "A review of the engineering properties of sea ice," Cold Regions Science and Technology, vol. 60, no. 2, pp. 107-129, 2010.

[5] E. M. Schulson, "Brittle failure of ice," Engineering Fracture Mechanics, vol. 68, no. 17-18, pp. 1839-1887, 2001.

[6] M. Storheim, E. Kim, J. Amdahl, and S. Ehlers, "Iceberg shape sensitivity in ship impact assessment in view of existing material models," in Proceedings of the ASME 31st International Conference on Ocean, Offshore and Arctic Engineering, 2012.

[7] N. Norsok, 004, Design of Steel Structures, Standards Norway, Rev 2, 2004.

[8] T. J. Sanderson, Ice Mechanics-Risks to Offshore Structures, Graham and Trotman, London, UK, 1988.

[9] D. M. Masterson, R. Frederking, B. Wright, T. Kärnä, and W. P. Maddock, "A revised ice pressure-area curve," in Proceedings of the 19th International Conference on Port and Ocean Engineering under Arctic Conditions, 2007.

[10] ISO/CD 19906, Petroleum and Natural Gas Industries-Arctic Offshore Structures, ISO TC 67/SC 7/WG8. Final Draft International Standard, International Standardisation Organization, Geneva, Switzerland, 2010.

[11] A. C. Palmer, J. P. Dempsey, and D. M. Masterson, "A revised ice pressure-area curve and a fracture mechanics explanation," Cold Regions Science and Technology, vol. 56, no. 2-3, pp. 73-76, 2009.

[12] G. W. Timco and D. Sudom, "Revisiting the Sanderson pressure-area curve: defining parameters that influence ice pressure," Cold Regions Science and Technology, vol. 95, pp. 5366, 2013.

[13] R. E. Gagnon, "A numerical model of ice crushing using a foam analogue," Cold Regions Science and Technology, vol. 65, no. 3, pp. 335-350, 2011.

[14] C. Jebaraj, A. S. J. Swamidas, L. Y. Shih, and K. Munaswamy, "Finite element analysis of ship/ice interaction," Computers and Structures, vol. 43, no. 2, pp. 205-221, 1992.

[15] R. von Bock, U. Polach, and S. Ehlers, "Model scale ice-part B: numerical model," Cold Regions Science and Technology, vol. 94, pp. 53-60, 2013.

[16] R. Gagnon, "Analysis of data from bergy bit impacts using a novel hull-mounted external impact panel," Cold Regions Science and Technology, vol. 52, no. 1, pp. 50-66, 2008.

[17] A. Derradji-Aouat, "A unified failure envelope for isotropic fresh water ice and iceberg ice," in Proceedings of ETCE/OMAE Joint Conference Energy for the New Millenium, 2000.

[18] J. C. Simo and T. J. R. Hughes, Computational Inelasticity, vol. 7 of Interdisciplinary Applied Mathematics, Springer, New York, NY, USA, 2008.
[19] Z. Liu, J. Amdahl, and S. Løset, "Plasticity based material modelling of ice and its application to ship-iceberg impacts," Cold Regions Science and Technology, vol. 65, no. 3, pp. 326-334, 2011.

[20] R. E. Gagnon and P. H. Gammon, "Triaxial experiments on iceberg and glacier ice," Journal of Glaciology, vol. 41, no. 139, pp. 528-540, 1995.

[21] J. O. Hallquist, LS-DYNA: Keyword User's Manual, Livermore Software Technology, Livermore, Calif, USA, 2007.

[22] Z. Liu, J. Amdahl, and S. Løset, "Integrated numerical analysis of an iceberg collision with a foreship structure," Marine Structures, vol. 24, no. 4, pp. 377-395, 2011.

[23] I. J. Jordaan, "Mechanics of ice-structure interaction," Engineering Fracture Mechanics, vol. 68, no. 17-18, pp. 1923-1960, 2001.

[24] E. Kim, M. Storheim, R. V. B. Und Polach, and J. Amdahl, "Design and modelling of accidental ship collisions with ice masses at laboratory-scale," in Proceedings of the ASME 31st International Conference on Ocean, Offshore and Arctic Engineering, American Society of Mechanical Engineers, 2012. 


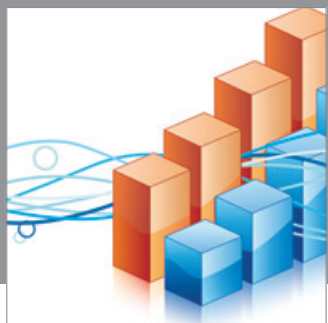

Advances in

Operations Research

mansans

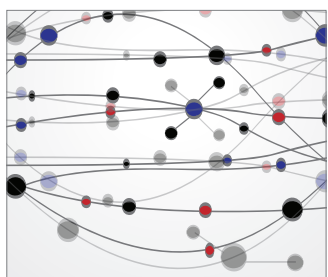

The Scientific World Journal
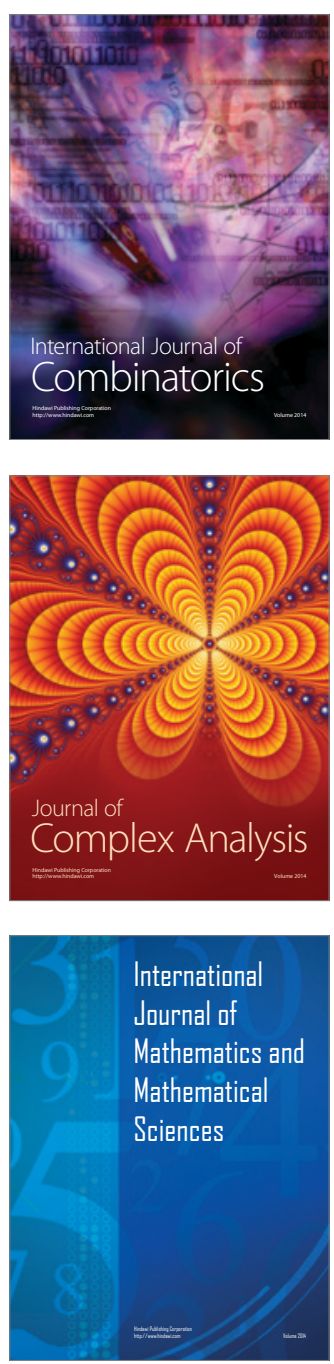
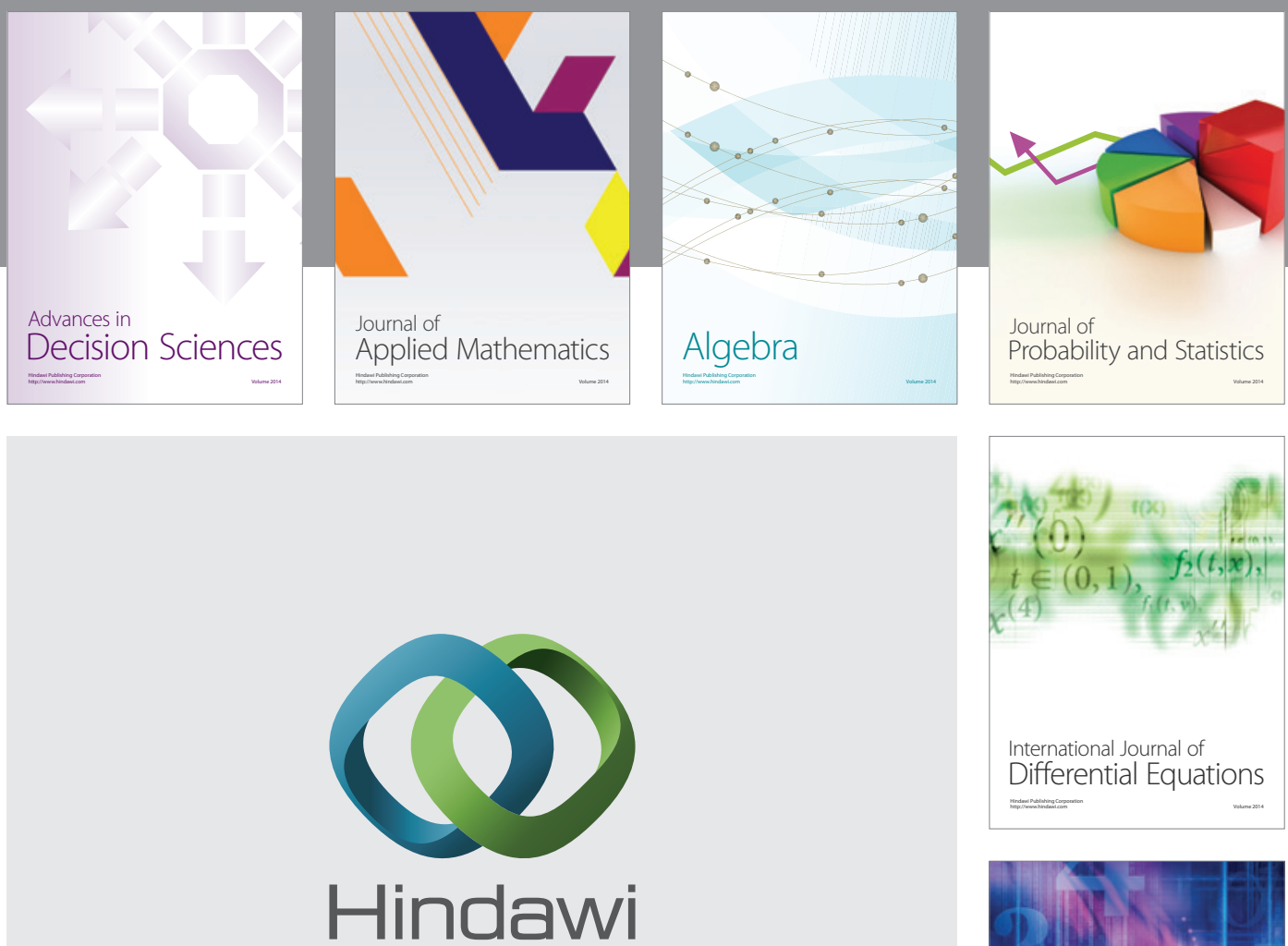

Submit your manuscripts at http://www.hindawi.com
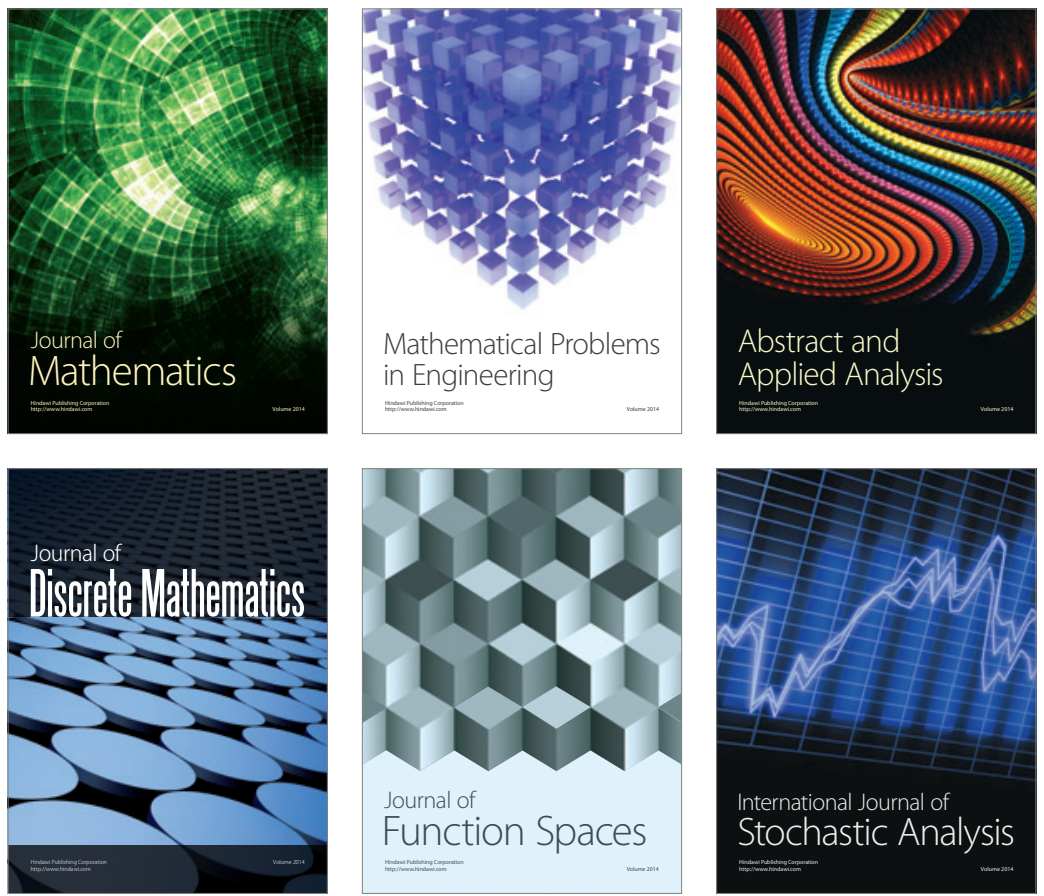

Journal of

Function Spaces

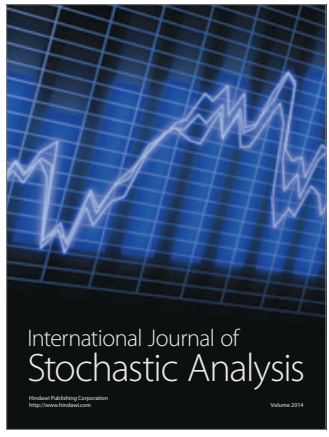

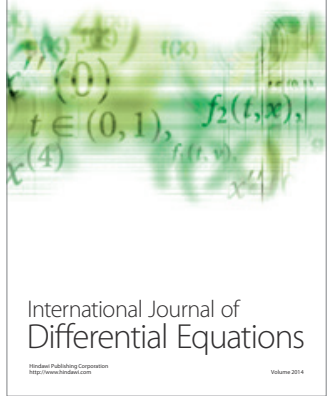
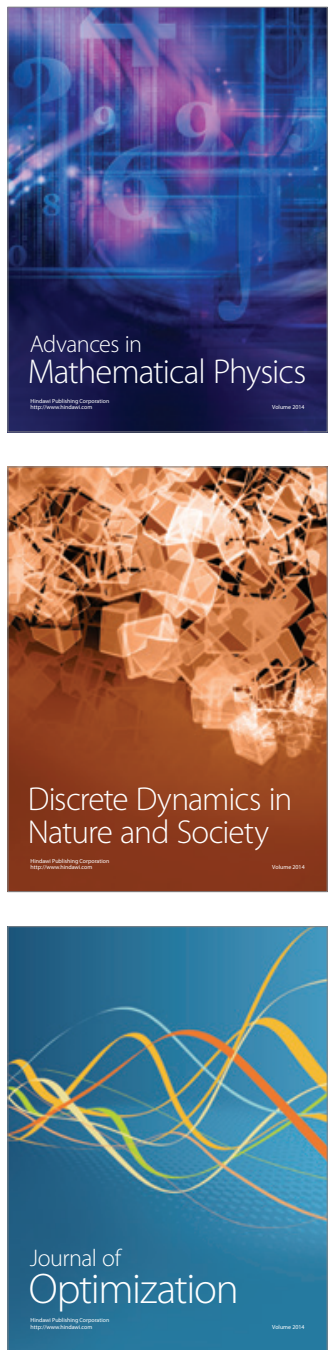